\title{
Analisis Biaya Operasional Kendaraan (BOK) Angkutan Kota Trayek Cimahi - Leuwipanjang Bandung
}

\author{
ELKHASNET, MUHAMMAD FATHURRAHMAN AL RASYID
}

Jurusan Teknik Sipil, Institut Teknologi Nasional Bandung

Email: elkha_ramaya@yahoo.com

\begin{abstract}
ABSTRAK
Banyaknya kendaraan angkutan kota trayek Cimahi-Leuwipanjang yang berhenti beroperasi dan dibiarkan terparkir di bawah jembatan layang menjadi bukti atas kegagalan sistem transportasi di Jawa Barat. Tujuan penelitian ini untuk menganalisis biaya operasional kendaraan (BOK) menggunakan Pedoman Teknis Penyelenggaraan Angkutan Penumpang Umum Di Wilayah Perkotaan Dalam Trayek Tetap dan Teratur dari Direktorat Jenderal Perhubungan Darat (SK.687/AJ.206/DRJD/2002) dan survei pengeluaran dan pendapatan angkutan kota trayek Cimahi - Leuwipanjang. Pengumpulan data melalui wawancara langsung dengan sopir dan data-data terkait dengan BOK yang tersedia di berbagai media. Dari penelitian ini dapat diketahui bahwa rata rata biaya operasional kendaraan angkutan kota trayek Cimahi - Leuwipanjang adalah Rp56.590.250,00 per tahun, sedangkan rata-rata pendapatan adalah Rp82.672.500,00 per tahun dan rata-rata pendapatan bersih adalah Rp26.082.250,00 per tahun atau Rp2.173.520,00 per bulan. Rendahnya pendapatan sopir atau pemilik menyebabkan banyak angutan kota yang tidak beroperasi.
\end{abstract}

Kata kunci: biaya operasional kendaraan, pendapatan, pendapatan bersih

\begin{abstract}
The large number of city transportation vehicles on the Cimahi - Leuwipanjang route that have stopped operating and parked under the flyover, is evidence of the failure of the transportation system in West Java. The purpose of this study was to analyze Vehicle Operating Costs (VOC) using the Technical Guidelines for the Implementation of Public Passenger Transportation in Urban Areas on Fixed and Regular Routes from the Directorate General of Land Transportation (SK.687/AJ.206/DRJD/2002) and survey of transportation expenses and income. Data was collected from interviews with the driver and from various media. From this research it obtained that the average operational cost of city transportation vehicles on Cimahi - Leuwipanjang route is Rp56,590,250,00 per year, while the income is Rp26,082,250,00 per year and the nett income is Rp2,173,520,00 per month. The low income of drivers or owners has caused many city transportation vehicles not to operate.
\end{abstract}

Key words: vehicle operating cost, income, nett income 


\section{PENDAHULUAN}

\subsection{Latar Belakang}

Perkembangan penduduk yang semakin meningkat maka berdampak pula pada perkembangan transportasi saat ini. Usaha untuk memenuhi kebutuhan pergerakan orang dan barang terus menerus dilakukan, namun ternyata belum banyak perubahan pada sistem transportasi di Jawa Barat. Angkutan umum seharusnya menjadi sarana transportasi yang paling banyak digunakan oleh masyarakat, tetapi pada realitanya angkutan umum semakin hari semakin menurun penggunaannya karena banyak yang beralih menggunakan sepeda motor, yang menjadikan sedikit berpengaruh terhadap perkembangan sosial dan ekonomi masyarakat. Contoh nyata dari dampak sistem transportasi yang buruk dapat dilihat pada angkutan kota trayek Cimahi - Leuwipanjang. Banyaknya kendaraan angkutan kota trayek Cimahi - Leuwipanjang yang berhenti beroperasi dan dibiarkan terparkir di bawah jembatan layang menjadi bukti atas kegagalan sistem transportasi di Jawa Barat.

\subsection{Latar Belakang}

Tujuan penelitian ini adalah:

1. Mengetahui rata-rata Biaya Operasional Kendaraan Angkutan Kota Trayek Cimahi Leuwipanjang.

2. Mengetahui rata-rata Pendapatan Kendaraan Angkutan Kota Trayek Cimahi Leuwipanjang.

3. Mengetahui rata-rata Pendapatan Bersih Kendaraan Angkutan Kota Trayek Cimahi Leuwipanjang.

\subsection{Manfaat Penelitian}

Manfaat dari penelitian ini adalah bisa menjadi bahan pertimbangan untuk Pemerintah Provinsi Jawa Barat dan Dinas Perhubungan Jawa Barat dalam membuat kebijakan yang berpengaruh terhadap sistem transportasi Jawa Barat.

\subsection{Ruang Lingkup}

Ruang lingkup penelitian ini adalah:

1. Wawancara dilakukan pada penyedia jasa angkutan kota yaitu pemilik kendaraan angkutan kota atau supir angkutan kota trayek Cimahi - Leuwipanjang.

2. Analisis Biaya Operasional Kendaraan (BOK) menggunakan Pedoman Teknis Penyelenggaraan Angkutan Penumpang Umum Di Wilayah Perkotaan Dalam Trayek Tetap Dan Terartur berupa Surat Keputusan yang dikeluarkan oleh Direktorat Jenderal Perhubungan Darat (SK.687/AJ.206/DRJD/2002).

3. Pendapatan Angkutan Kota Trayek Cimahi - Leuwipanjang.

\section{TINJAUAN PUSTAKA}

\subsection{Sistem Transportasi}

Sistem transportasi adalah suatu bentuk keterikatan antara penumpang, barang, prasarana dan sarana yang berinteraksi dalam rangka perpindahan orang atau barang, yang tercakup dalam suatu tatanan, baik secara alami ataupun buatan. Maksud diselenggarakan sistem transportasi adalah untuk mengkoordinasi proses pergerakan penumpang dan barang dengan mengatur komponen-komponennya dimana prasarana merupakan media untuk proses transportasi, sedangkan sarana merupakan alat yang digunakan dalam proses transportasi. Tujuan dari sistem transportasi sendiri adalah untuk mencapai proses transportasi penumpang dan barang secara maksimal dalam ruang dan waktu tertentu, dengan mempertimbangkan faktor keamanan, kenyamanan dan kelancaran, serta efisiensi waktu dan biaya. 


\subsection{Angkutan Umum}

Angkutan dapat didefinisikan sebagai pemindahan orang dan atau barang dari suatu tempat ke tempat lain dengan menggunakan kendaraan, sementara kendaraan umum adalah setiap kendaraan bermotor yang disediakan untuk digunakan oleh umum dengan dipungut biaya. Kendaraan umum dapat berupa mobil penumpang, bus kecil, bus sedang, dan bus besar. Angkutan kota atau biasa disebut angkot adalah transportasi umum dengan rute yang sudah ditentukan.

\subsection{Angkutan Kota}

Angkutan kota atau biasa disebut angkot adalah transportasi umum dengan rute yang sudah ditentukan. Angkutan kota atau angkot berbeda dengan bis antar kota karena selain jumlah penumpang yang dapat diangkut lebih sedikit, angkutan kota juga tidak mempunyai tempat pemberhentian khusus seperti bis antar kota. Karena angkutan kota tidak mempunyai tempat pemberhentian khusus, maka seringkali angkutan kota berhenti mendadak untuk menurunkan penumpang maupun menaikkan penumpang dan terkadang menepi dengan waktu yang lama untuk menunggu penumpang. Dalam penelitian ini, angkutan kota yang menjadi objek penelitian adalah Angkutan Kota Trayek Cimahi - Leuwipanjang dengan tipe kendaraan Mitsubitshi Colt T 120 SS 1,5.

\subsection{Biaya Operasional Kendaraan (BOK)}

Biaya Operasional Kendaraan (BOK) adalah biaya yang secara ekonomi terjadi karena dioperasikannya satu kendaraan pada kondisi normal untuk suatu tujuan tertentu. Perhitungan Biaya Operasional Kendaraan (BOK) pada penelitian ini menggunakan Pedoman Teknis Penyelenggaraan Angkutan Penumpang Umum Di Wilayah Perkotaan Dalam Trayek Tetap Dan Terartur berupa Surat Keputusan yang dikeluarkan oleh Direktorat Jenderal Perhubungan Darat (SK.687/AJ.206/DRJD/2002).

\subsection{Pendapatan Bersih}

Pendapatan bersih merupakan hasil yang diperoleh sopir kendaraan angkutan kota maupun pemilik kendaraan angkutan kota selama angkutan kota tersebut beroperasi. Pendapatan bersih sopir kendaraan angkutan kota maupun pemilik kendaraan angkutan kota dapat dihitung dengan cara pendapatan yang didapat dikurangi biaya untuk operasional kendaraan tersebut.

\subsection{Ukuran Sampel}

Teknik sampling adalah cara untuk menentukan sampel yang jumlahnya sesuai dengan ukuran sampel yang akan dijadikan sumber data sebenarnya, dengan memperhatikan sifat-sifat dan penyebaran populasi agar diperoleh sampel yang representatif (Margono, S., 2005). Dalam penelitian ini, rumus yang digunakan untuk menentukan ukuran sampel yaitu menggunakan metode Slovin seperti terlihat pada Persamaan 1 berikut:

$$
n=\frac{N}{1+N e^{2}}
$$

dengan:

$n$ = besar sampel minimum,

$N=$ populasi angkutan kota trayek Cimahi - Leuwipanjang,

$e^{2}=$ tingkat kesalahan 
Penelitian dengan derajat kepercayaan 95\%, maka tingkat kesalahan yang dimasukan kedalam rumus adalah $5 \%$. Derajat kepercayaan pada penelitian ini adalah sebesar $80 \%$ sedangkan tingkat kesalahan pada penelitian ini adalah sebesar $20 \%$. Data populasi angkutan kota trayek Cimahi - Leuwipanjang didapatkan melalui wawancara langsung kepada Ketua Dewan Pimpinan Cabang Kota Cimahi Organisasi Pengusaha Nasional Angkutan Bermotor Di Jalan Raya yaitu sekitar 1.000 unit, maka jumlah sampel yang diperoleh melalui perhitungan menggunakan metode slovin adalah:

$$
n=\frac{N}{1+N e^{2}}=\frac{1000}{1+\left(1000 \times 0,20^{2}\right)}=24 \text { sampel }
$$

Karena keterbatasan waktu dalam melakukan wawancara di lapangan, maka dalam penelitian ini hanya mengambil 20 sampel angkutan kota yang beroperasi.

\section{METODOLOGI PENELITIAN}

\subsection{Identifikasi Masalah}

Permasalahan yang terjadi adalah buruknya sistem transportasi yang dapat dilihat pada angkutan kota trayek Cimahi - Leuwipanjang. Banyaknya kendaraan angkutan kota trayek Cimahi - Leuwipanjang yang berhenti beroperasi dan dibiarkan terparkir dibawah jembatan layang menjadi potret yang sangat menyedihkan atas buruknya sistem transportasi di Jawa Barat.

\subsection{Survei Pendahuluan}

Tujuan dilakukannya survei pendahuluan adalah agar dapat mengetahui kondisi yang sebenarnya di lapangan ketika masalah sudah teridentifikasi. Survei pendahuluan dilakukan dengan cara mendatangi lokasi-lokasi yang dibutuhkan untuk penelitian ini.

\subsection{Pengumpulan Data}

Pengumpulan data yang dibutuhkan pada penelitian tugas akhir ini adalah data primer dan data sekunder. Data primer ini merupakan data yang diperoleh dari hasil wawancara langsung terhadap sopir angkutan kota dan pemilik angkutan kota trayek Cimahi - Leuwipanjang, sedangkan data sekunder adalah data yang diambil dari berbagai sumber yang sudah tersedia.

\subsection{Pengolahan dan Perhitungan Data}

Data-data yang telah didapat kemudian diolah untuk menjadi data atau hasil yang diteliti pada tugas akhir ini. Data-data tersebut nantinya diolah dan akan menghasilkan Biaya Operasional Kendaraan (BOK) dan juga dibandingkan dengan Pendapatan Angkutan Kota Trayek Cimahi Leuwipanjang.

\subsection{Analisis Data}

Setelah melakukan pengumpulan dan pengolahan data, maka masuk kedalam tahap analisis data. Analisis yang dilakukan adalah dengan cara membandingkan antara Biaya Operasional Kendaraan (BOK) dan pendapatan. Dari analisis tersebut maka dapat menjadi bahan pembahasan untuk mengetahui penyebab banyaknya angkutan kota trayek Cimahi Leuwipanjang yang berhenti beroperasi.

\section{HASIL PENELITIAN DAN PEMBAHASAN}

Perhitungan biaya operasional kendaraan (BOK) angkutan kota trayek Cimahi - Leuwipanjang menggunakan Surat Keputusan Direktorat Jenderal Perhubungan Darat Republik Indonesia (SK.687/AJ.206/DRJD/2002). 
Karena kondisi di lapangan berbeda dengan komponen rumus yang diambil dari Surat Keputusan Direktorat Jenderal Perhubungan Darat Republik Indonesia (SK.687/AJ.206/DRJD/2002), maka komponen rumus yang digunakan dalam penelitian ini untuk menghitung Biaya Operasional Kendaraan Angkutan Kota Trayek Cimahi - Leuwipanjang per Tahun Biaya Tetap per Tahun adalah:

a. Biaya Penyusutan $(B P)$

Masa penyusutan kendaraan penumpang umum pada Surat Keputusan Direktorat Jenderal Perhubungan Darat tahun 2002 ditetapkan 5 tahun, tetapi kondisi di lapangan umur angkutan kota adalah 15 tahun, oleh karena itu diambil nilai tengah masa penyusutan $(M P)$ yaitu 10 tahun.

Harga kendaraan $(H K)$ Rp. 60.000.000,- dengan merek mobil Mitsubitshi Colt T 120 SS 1,5. Harga tersebut adalah harga kendaraan pada tahun 2010 yang didapat melalui wawancara terhadap pemilik mobil. Nilai residu (SV) mobil penumpang umum adalah $20 \%$ dari harga kendaraan.

Biaya penyusutan (depresiasi) kendaraan per tahun dapat dihitung dengan Persamaan 2 berikut:

$$
\begin{gathered}
B P=\frac{H K-S V}{M P} \\
B P=\frac{\mathrm{Rp} 60.000 .000,00-(20 \% \times \mathrm{Rp} 60.000 .000,00)}{10}=\mathrm{Rp} 4.800 .000,00 \text { per tahun }
\end{gathered}
$$

b. Biaya Bunga Modal $\left(B B M_{0}\right)$

Kendaraan dibeli tunai oleh pemilik, sehingga keuntungan yang diperoleh pemilik diperhitungan lebih besar dari bunga deposito dengan asumsi 8 persen per tahun. Biaya bunga modal per tahun dapat dihitung dengan Persamaan 3 berikut:

$$
\begin{gathered}
B B M_{0}=0,08 \times H K \\
B B M_{0}=0,08 \times \mathrm{Rp} 60.000 .000,00=\mathrm{Rp} 4.800 .000,00 \text { per tahun }
\end{gathered}
$$

C. Biaya Administrasi $(B A)$

Biaya administrasi kendaraan angkutan kota terdiri dari biaya pajak kendaraan bermotor per tahun ( $P K B$ ) sebesar Rp700.000,00; biaya kir per tahun $(K I R)$ sebesar Rp300.000,00; biaya izin usaha per tahun $(I U)$, biaya asuransi jasa raharja per tahun $(J R)$, biaya izin trayek per tahun (IT) sebesar Rp250.000,00. Adapun biaya administrasi kendaraan dapat dihitung dengan Persamaan 4 berikut:

$$
\begin{gathered}
B A=P K B+K I R+I T \\
B A=\mathrm{Rp} 700.000,00+\mathrm{Rp} 300.000,00+\mathrm{Rp} 250.000,00=\mathrm{Rp} 1.250 .000,00 \text { per tahun }
\end{gathered}
$$

d. Biaya Bahan Bakar Minyak ( $B B B M)$

Asumsi biaya bahan bakar minyak dasar Rp120.000,00 dengan waktu penggunaan $\left(H_{0}\right)$ bahan bakar 1 tahun. Maka, biaya bahan bakar minyak per tahun dapat dihitung dengan Persamaan 5 sebagai berikut:

$$
B B B M=B B B M \times H_{0}
$$




$$
B B B M=\mathrm{Rp} 120.000,00 \times 365=\mathrm{Rp} 43.800 .000,00 \text { per tahun }
$$

e. Biaya Ban $(B B)$

Asumsi penggantian ban angkutan kota dilakukan setahun sekali membutuhkan jumlah ban $(J P B)$ sebanyak 2 buah. Harga satu ban bermacam-macam tergantung merek ban. Dalam perhitungan ini harga ban $(H B)$ diasumsikan sebesar Rp500.000,00/buah. Maka, biaya ban per tahun dapat dihitung dengan Persamaan 6 berikut:

$$
\begin{gathered}
B B=\frac{1}{D T} \times J P B \times H B \\
B B=\frac{1}{35.000} \times 2 \times \mathrm{Rp} 500.000,00=\mathrm{Rp} 30,45 \text { per } \mathrm{km} \\
B B=\mathrm{Rp} 30,45 \times 90=\mathrm{Rp} 2.740,50 \text { per hari } \\
B B=\mathrm{Rp} 2.740,50 \times 365=\mathrm{Rp} 1.000 .000,00 \text { per tahun }
\end{gathered}
$$

f. Biaya Penggantian Aki (BPA)

Asumsi penggantian aki dilakukan dengan jangka waktu (JPA) 1 tahun sekali dengan harga aki $(H A)$ sebesar Rp450.000,00 sudah termasuk biaya pemasangan. Biaya penggantian aki per tahun dapat dihitung dengan Persamaan 7 berikut:

$$
\begin{gathered}
B P A=J P A \times H A \\
B P A=1 \times \mathrm{Rp} 45.000,00=\mathrm{Rp} 450.000,00 \text { per tahun }
\end{gathered}
$$

g. Biaya Service Kecil (BSK)

Asumsi service kecil yang dilakukan adalah penggantian oli dan pembersihan filter udara. Service kecil dilakukan dengan asumsi jangka waktu 1 bulan sekali dan biaya sebesar Rp200.000,00 termasuk biaya pemasangan dan pembersihan filter udara $(B B a+O S)$. Biaya service kecil per tahun dapat dihitung dengan Persamaan 8 berikut:

$$
\begin{gathered}
B S K=(B B a+O S) \times 12 \\
B P A=\mathrm{Rp} 200.000,00 \times 12=\mathrm{Rp} 240.000,00 \text { per tahun }
\end{gathered}
$$

h. Biaya Service Besar (BSB)

Asumsi service besar yang dilakukan adalah (penggantian oli mesin, oli transmisi, oli gardan, tune up). Asumsi jangka waktu service besar adalah 6 bulan sekali dan harga sebesar Rp475.000,00 sedangkan penggantian kampas rem dilakukan dengan asumsi jangka waktu 4 bulan sekali dan harga sebesar Rp317.000,00 $(B B a+O S)$. Biaya service besar per tahun dapat dihitung dengan Persamaan 9 berikut:

$$
\begin{gathered}
B S B=B B a+O S \\
B P A=(\operatorname{Rp} 475.000,00 \times 2)+(\operatorname{Rp} 317.000,00 \times 3)=\mathrm{Rp} 1.900 .000,00 \text { per tahun }
\end{gathered}
$$


Tabel 1. Biaya Operasional Kendaraan Angkutan Kota Trayek Cimahi - Leuwipanjang per Tahun

\begin{tabular}{|c|c|c|c|c|c|c|c|c|c|c|c|c|}
\hline \multirow[b]{2}{*}{ No. } & \multirow[b]{2}{*}{$\begin{array}{c}\text { Plat } \\
\text { Nomor } \\
\text { Kendaraan }\end{array}$} & \multirow[b]{2}{*}{$\begin{array}{c}\text { Penyusutan } \\
\text { [Rp] }\end{array}$} & \multirow[b]{2}{*}{$\begin{array}{c}\text { Bunga } \\
\text { Modal } \\
\text { [Rp] }\end{array}$} & \multirow[b]{2}{*}{$\begin{array}{l}\text { Pajak } \\
\text { [Rp] }\end{array}$} & \multirow[b]{2}{*}{$\begin{array}{l}\text { KIR } \\
\text { [Rp] }\end{array}$} & \multicolumn{2}{|c|}{ Biaya Langsung Per Tahun } & \multirow[b]{2}{*}{$\begin{array}{l}\text { Ban } \\
{[R p]}\end{array}$} & \multirow[b]{2}{*}{$\begin{array}{c}\text { Aki } \\
{[R p]}\end{array}$} & \multirow[b]{2}{*}{$\begin{array}{c}\text { Service } \\
\text { Kecil } \\
\text { [Rp] }\end{array}$} & \multirow[b]{2}{*}{$\begin{array}{c}\text { Service } \\
\text { Besar } \\
\text { [Rp] }\end{array}$} & \multirow[b]{2}{*}{$\begin{array}{c}\text { Total } \\
\text { Per Tahun } \\
\text { [Rp] }\end{array}$} \\
\hline & & & & & & $\begin{array}{c}\text { Izin } \\
\text { Trayek } \\
\text { [Rp] }\end{array}$ & $\begin{array}{l}\text { BBM } \\
\text { [Rp] }\end{array}$ & & & & & \\
\hline 1 & D 1907 TZ & $4.800 .000,00$ & $4.800 .000,00$ & $700.000,00$ & $300.000,00$ & $250.000,00$ & $43.800 .000,00$ & $1.000 .000,00$ & $450.000,00$ & $2.400 .000,00$ & $1.900 .000,00$ & $60.400 .000,00$ \\
\hline 2 & D 1990 ED & $4.800 .000,00$ & $4.800 .000,00$ & $480.000,00$ & $350.000,00$ & $250.000,00$ & $40.150 .000,00$ & $1.000 .000,00$ & $450.000,00$ & $2.400 .000,00$ & $1.900 .000,00$ & $56.580 .000,00$ \\
\hline 3 & D 1997 CA & $4.800 .000,00$ & $4.800 .000,00$ & $600.000,00$ & $375.000,00$ & $250.000,00$ & $36.325 .000,00$ & $1.000 .000,00$ & $450.000,00$ & $2.400 .000,00$ & $1.900 .000,00$ & $52.900 .000,00$ \\
\hline 4 & D 1975 W & $4.800 .000,00$ & $4.800 .000,00$ & $500.000,00$ & $300.000,00$ & $250.000,00$ & $38.325 .000,00$ & $1.000 .000,00$ & $450.000,00$ & $2.400 .000,00$ & $1.900 .000,00$ & $54.725 .000,00$ \\
\hline 5 & D 1998 TV & $4.800 .000,00$ & $4.800 .000,00$ & $700.000,00$ & $300.000,00$ & $250.000,00$ & $40.150 .000,00$ & $1.000 .000,00$ & $450.000,00$ & $2.400 .000,00$ & $1.900 .000,00$ & $56.750 .000,00$ \\
\hline 6 & D 1986 OW & $4.800 .000,00$ & $4.800 .000,00$ & $520.000,00$ & $400.000,00$ & $250.000,00$ & $38.325 .000,00$ & $1.000 .000,00$ & $450.000,00$ & $2.400 .000,00$ & $1.900 .000,00$ & $54.845 .000,00$ \\
\hline 7 & D 1921 NC & $4.800 .000,00$ & $4.800 .000,00$ & $535.000,00$ & $300.000,00$ & $250.000,00$ & $43.800 .000,00$ & $1.000 .000,00$ & $450.000,00$ & $2.400 .000,00$ & $1.900 .000,00$ & $60.235 .000,00$ \\
\hline 8 & D 1932 RT & $4.800 .000,00$ & $4.800 .000,00$ & $615.000,00$ & $400.000,00$ & $250.000,00$ & $40.150 .000,00$ & $1.000 .000,00$ & $450.000,00$ & $2.400 .000,00$ & $1.900 .000,00$ & $56.765 .000,00$ \\
\hline 9 & D 1943 PS & $4.800 .000,00$ & $4.800 .000,00$ & $735.000,00$ & $310.000,00$ & $250.000,00$ & $36.500 .000,00$ & $1.000 .000,00$ & $450.000,00$ & $2.400 .000,00$ & $1.900 .000,00$ & $53.145 .000,00$ \\
\hline 10 & D 1933 BM & $4.800 .000,00$ & $4.800 .000,00$ & $450.000,00$ & $300.000,00$ & $250.000,00$ & $38.325 .000,00$ & $1.000 .000,00$ & $450.000,00$ & $2.400 .000,00$ & $1.900 .000,00$ & $54.675 .000,00$ \\
\hline 11 & D 1905 GE & $4.800 .000,00$ & $4.800 .000,00$ & $400.000,00$ & $310.000,00$ & $250.000,00$ & $36.500 .000,00$ & $1.000 .000,00$ & $450.000,00$ & $2.400 .000,00$ & $1.900 .000,00$ & $52.810 .000,00$ \\
\hline 12 & D $1953 \mathrm{FT}$ & $4.800 .000,00$ & $4.800 .000,00$ & $720.000,00$ & $300.000,00$ & $250.000,00$ & $40.150 .000,00$ & $1.000 .000,00$ & $450.000,00$ & 2.400 .000 & 1.900 & $56.770 .000,00$ \\
\hline 13 & D 1994 AC & $4.800 .000,00$ & $4.800 .000,00$ & $620.000,00$ & $350.000,00$ & $250.000,00$ & $40.380 .000,00$ & $1.000 .000,00$ & $450.000,00$ & $2.400 .000,00$ & $1.900 .000,00$ & $56.950 .000,00$ \\
\hline 14 & D 1965 XA & $4.800 .000,00$ & $4.800 .000,00$ & $535.000,00$ & $300.000,00$ & $250.000,00$ & $40.150 .000,00$ & $1.000 .000,00$ & $450.000,00$ & $2.400 .000,00$ & $1.900 .000,00$ & $56.585 .000,00$ \\
\hline 15 & D 1958 TV & $4.800 .000,00$ & $4.800 .000,00$ & $475.000,00$ & $300.000,00$ & $250.000,00$ & $36.500 .000,00$ & $1.000 .000,00$ & $450.000,00$ & $2.400 .000,00$ & $1.900 .000,00$ & $52.875 .000,00$ \\
\hline 16 & D 1923 MA & $4.800 .000,00$ & $4.800 .000,00$ & $700.000,00$ & $300.000,00$ & $250.000,00$ & $43.800 .000,00$ & $1.000 .000,00$ & $450.000,00$ & $2.400 .000,00$ & $1.900 .000,00$ & $60.400 .000,00$ \\
\hline 17 & D 1987 OP & $4.800 .000,00$ & $4.800 .000,00$ & $500.000,00$ & $350.000,00$ & $250.000,00$ & $43.800 .000,00$ & $1.000 .000,00$ & $450.000,00$ & $2.400 .000,00$ & $1.900 .000,00$ & $60.250 .000,00$ \\
\hline 18 & D 1967 KC & $4.800 .000,00$ & $4.800 .000,00$ & $615.000,00$ & $400.000,00$ & $250.000,00$ & $40.150 .000,00$ & $1.000 .000,00$ & $450.000,00$ & $2.400 .000,00$ & $1.900 .000,00$ & $56.765 .000,00$ \\
\hline 19 & D 1991 IA & $4.800 .000,00$ & $4.800 .000,00$ & $600.000,00$ & $325.000,00$ & $250.000,00$ & $36.500 .000,00$ & $1.000 .000,00$ & $450.000,00$ & $2.400 .000,00$ & $1.900 .000,00$ & $53.025 .000,00$ \\
\hline \multirow[t]{2}{*}{20} & D 1955 XW & $4.800 .000,00$ & $4.800 .000,00$ & $710.000,00$ & $300.000,00$ & $250.000,00$ & $43.800 .000,00$ & $1.000 .000,00$ & $450.000,00$ & $2.400 .000,00$ & $1.900 .000,00$ & $60.410 .000,00$ \\
\hline & Rata-rata & $4.800 .000,00$ & $4.800 .000,00$ & $585.500,00$ & $328.500,00$ & $250.000,00$ & $40.058 .750,00$ & $1.000 .000,00$ & $450.000,00$ & $2.400 .000,00$ & $1.900 .000,00$ & $56.590 .250,00$ \\
\hline
\end{tabular}


Tabel 2. Biaya Operasional Kendaraan Angkutan Kota Trayek Cimahi - Leuwipanjang per Tahun

\begin{tabular}{ccccc}
\hline No. & $\begin{array}{c}\text { Plat Nomor } \\
\text { Kendaraan }\end{array}$ & $\begin{array}{c}\text { Pendapatan } \\
\text { per Tahun } \\
\text { [Rp] }\end{array}$ & $\begin{array}{c}\text { BoK Langsung } \\
\text { per Tahun } \\
\text { [Rp] }\end{array}$ & $\begin{array}{c}\text { Pendapatan Bersih } \\
\text { per Tahun } \\
\text { [Rp] }\end{array}$ \\
\hline 1 & D 1907 TZ & $80.300 .000,00$ & $60.400 .000,00$ & $19.900 .000,00$ \\
\hline 2 & D 1990 ED & $91.250 .000,00$ & $56.580 .000,00$ & $34.670 .000,00$ \\
\hline 3 & D 1997 CA & $80.300 .000,00$ & $53.075 .000,00$ & $27.225 .000,00$ \\
\hline 4 & D 1975 AW & $91.250 .000,00$ & $55.075 .000,00$ & $36.175 .000,00$ \\
\hline 5 & D 1998 TV & $80.300 .000,00$ & $56.750 .000,00$ & $23.550 .000,00$ \\
\hline 6 & D 1986 OW & $73.000 .000,00$ & $54.845 .000,00$ & $18.155 .000,00$ \\
\hline 7 & D 1921 NC & $80.300 .000,00$ & $60.235 .000,00$ & $20.065 .000,00$ \\
\hline 8 & D 1932 RT & $80.300 .000,00$ & $56.765 .000,00$ & $23.535 .000,00$ \\
\hline 9 & D 1943 PS & $91.250 .000,00$ & $53.145 .000,00$ & $38.105 .000,00$ \\
\hline 10 & D 1933 BM & $91.250 .000,00$ & $54.675 .000,00$ & $36.575 .000,00$ \\
\hline 11 & D 1905 GE & $98.550 .000,00$ & $52.810 .000,00$ & $45.740 .000,00$ \\
\hline 12 & D 1953 FT & $73.000 .000,00$ & $56.770 .000,00$ & $16.230 .000,00$ \\
\hline 13 & D 1994 AC & $91.250 .000,00$ & $60.370 .000,00$ & $30.880 .000,00$ \\
\hline 14 & D 1965 XA & $91.250 .000,00$ & $56.585 .000,00$ & $34.665 .000,00$ \\
\hline 15 & D 1958 TV & $73.000 .000,00$ & $52.875 .000,00$ & $20.125 .000,00$ \\
\hline 16 & D 1923 MA & $80.300 .000,00$ & $60.400 .000,00$ & $19.900 .000,00$ \\
\hline 17 & D 1987 OP & $80.300 .000,00$ & $60.250 .000,00$ & $20.050 .000,00$ \\
\hline 18 & D 1967 KC & $80.300 .000,00$ & $56.765 .000,00$ & $23.535 .000,00$ \\
\hline 19 & D 1991 IA & $73.000 .000,00$ & $53.025 .000,00$ & $19.975 .000,00$ \\
\hline 20 & D 1955 XW & $73.000 .000,00$ & $60.410 .000,00$ & $12.590 .000,00$ \\
\hline & Rata - Rata & $\mathbf{8 2 . 6 7 2 . 5 0 0 , 0 0}$ & $\mathbf{5 6 . 5 9 0 . 2 5 0 , 0 0}$ & $\mathbf{2 6 , 0 8 2 , 2 5 0 , 0 0}$ \\
\hline
\end{tabular}

Dari seluruh perhitungan di atas maka dapat diketahui bahwa rata rata Biaya Operasional Kendaraan (BOK) Angkutan Kota Trayek Cimahi - Leuwipanjang adalah Rp56.590.250,00 sedangkan rata-rata pendapatan Angkutan kota trayek Cimahi - Leuwipanjang adalah Rp82.672.500,00 per tahun dan rata-rata pendapatan bersih angkutan kota trayek Cimahi Leuwipanjang adalah Rp26.082.250,00 per tahun atau Rp2.173.520,00 per bulan.

\section{KESIMPULAN}

Setelah dilakukan perhitungan dan analisis data, maka dapat disimpulkan:

1. Kondisi di lapangan angkutan kota trayek Cimahi - Leuwipanjang beroperasi pada jam-jam tertentu saja yaitu berangkat kerja, berangkat sekolah, pulang kerja, dan pulang sekolah dikarenakan jam-jam tersebut adalah aktivitas para penumpang angkutan kota trayek Cimahi - Leuwipanjang, sedangkan selain pada jam-jam tersebut penumpang angkutan kota trayek Cimahi - Leuwipanjang sangat sedikit jumlahnya.

2. Angkutan kota trayek Cimahi - Leuwipanjang hanya beroperasi 3 RIT per hari. Jika di asumsikan waktu perjalanan untuk 1 RIT adalah 1 jam 12 menit, maka asumsi waktu perjalanan 3 RIT adalah 3 jam 36 menit. Seharusnya angkutan kota trayek Cimahi Leuwipanjang bisa beroperasi lebih dari 3 RIT per hari, sehingga pendapatan angkutan kota trayek Cimahi-Leuwipanjang dapat melebihi rata-rata yang sudah dihitung di atas.

3. Pengeluaran terbesar adalah BBM yaitu sekitar Rp40.058.750,00 per tahun atau sekitar $70 \%$ dari total BOK, oleh karena itu perlu dipertimbangkan subsisdi untuk angkutan umum, sehingga pengeluaran dapat ditekan.

4. Rata-rata pendapatan bersih angkutan kota trayek Cimahi - Leuwipanjang adalah Rp26.082.250,00 per tahun atau Rp2.173.520,00 per bulan; dimana angka ini lebih rendah dari UMR, sehingga membuat sopir tidak tertarik untuk mengoperasikannya.

\section{DAFTAR RUJUKAN}

Margono, S. (2005). Metodologi Penelitian Pendidikan. Jakarta: Rineka Cipta. 
Analisis Biaya Operasional Kendaraan (BOK) Angkutan Kota

Trayek Cimahi - Leuwipanjang Bandung

SK Dirjen Perhubungan Darat No.687/AJ.206/DRJD/2002. (2002). Pedoman Teknis Penyelenggaraan Angkutan Penumpang Umum di Wilayah Perkotaan Dalam Trayek Tetap dan Teratur. Jakarta: Kementrian Perhubungan Republik Indonesia. 